\title{
Digital dermoscopy to determine skin melanin index as an objective indicator of skin pigmentation
}

\author{
Sara Majewski ${ }^{1}$, Chantelle Carneiro ${ }^{1}$, Erin Ibler ${ }^{1}$, Peter Boor ${ }^{1}$, Gary Tran $^{1}$, \\ Mary C Martini ${ }^{1,2}$, Salvatore Di Loro ${ }^{3}$, Alfred W Rademaker ${ }^{2,4}$, Dennis P West ${ }^{1,2}$, \\ Beatrice Nardone $^{1^{*}}$ \\ ${ }^{1}$ Department of Dermatology, Feinberg School of Medicine, Northwestern University, Chicago, IL \\ ${ }^{2}$ Robert H. Lurie Comprehensive Cancer Center, Northwestern University, Chicago, IL \\ ${ }^{3}$ Department of Information Technology, Telecom Italia Group, Rome, Italy \\ ${ }^{4}$ Department of Preventive Medicine, Feinberg School of Medicine, Northwestern University, Chicago, IL
}

\begin{abstract}
Clinical assessment of skin photosensitivity is subjectively determined by erythema and tanning responses to sunlight recalled by the subject, alternatively known as Fitzpatrick Skin Phototype (SPT). Responses may be unreliable due to recall bias, subjective bias by clinicians and subjects, and lack of cultural sensitivity of the questions. Analysis of red-green-blue (RGB) color spacing of digital images may provide an objective determination of SPT. This paper presents the studies to assess the melanin index (MI), as determined by RGB images obtained by both standard digital camera as well as by videodermoscope, and to correlate the MI with SPT based upon subjects' verbal responses to standardized questions administered by a dermatologist.

A sample of subjects representing all SPTs I-VI was selected. Both the digital camera and videodermoscope were calibrated at standard illumination, light source and white balance. Images of constitutive skin of the upper ventral arm were taken of each subject using both instruments. The studies showed that 58 subjects (20 M, 38 F) were enrolled in the study (mean age: 47 years; range: $20-89$ ), stratified to skin phototype I-VI. MI obtained by using both digital camera and videodermoscope increased significantly as the SPT increased $(p=0.004$ and $p<0.0001$, respectively) and positively correlated with dermatologist-assessed SPT (Spearman correlation, $r=0.48$ and $r=0.84$, respectively). Digital imaging can quantify melanin content in order to quantitatively approximate skin pigmentation in all skin phototypes including Type VI skin. This methodology holds promise as a simple, non-invasive, rapid and objective approach to reliably determine skin phototype and, with further investigation, may prove to be both practical and useful in the prediction of skin cancer risk.
\end{abstract}

Keywords: Melanin Index; Fitzpatrick Skin Phototype; digital imaging

Citation: Majewski S, Carneiro C, Ibler E, Boor P, Tran G, et al. Digital dermoscopy to determine skin melanin index as an objective indicator of skin pigmentation. J Surg Dermatol 2016; 1(1): 37-42; http://dx.doi.org /10.18282/jsd. v1.i1.15.

*Correspondence to: Beatrice Nardone, Department of Dermatology, Northwestern University, 676 N. St. Clair Suite 1600, Chicago, IL 60611, USA, b-nardone@ northwestern.edu.

Received: $11^{\text {th }}$ December 2015; Accepted: $3^{\text {rd }}$ February 2016; Published Online: $14^{\text {th }}$ April 2016

Copyright (C) 2016 Majewski S, et al. This is an Open Access article distributed under the terms of the Creative Commons Attribution-Non Commercial 4.0 International License (http://creativecommons.org/licenses/by-nc/4.0/), permitting all non-commercial use, distribution, and reproduction in any medium, provided the original work is properly cited. 


\section{Introduction}

For several decades, clinical assessment of photosensitivity has been based on the SPT ${ }^{[1]}$. As originally designed, the standardized questions about the ease of burning and tanning reactions to the first sun exposure in the summer were administered by trained personnel, especially those in dermatology, and the clinicians determined the SPTbased on the patient's responses ${ }^{[1]}$. Over the years, the standardized questions were used in written surveys. By relying on patient's memory of sun burning and tanning, recall bias may be introduced. Furthermore, clinicians have evolved to visually assess the SPT without asking the patient to recall their skin reaction to ultraviolet light (UVL). Subjective assessment of SPT by clinicians was heavily influenced by patients' hair and eye color ${ }^{[2]}$. Since SPT was correlated with susceptibility to developing skin cancer, errors in determining the subject's SPT contribute to misunderstanding of their susceptibility to skin cancer and need for sun protection.

Various in vitro and in vivo methods to quantify skin pigmentation have been proposed and evaluated to avoid subjective bias in SPT but none have successfully differentiated all 6 phototypes ${ }^{[2]}$. Over the last decade, non-invasive instrumentation has been utilized to assess pigmentation in vivo including spectrophotometry ${ }^{[3]}$, colorimetry $^{[4]}$, skin color scale chart ${ }^{[5]}$, fiber optic sensor ${ }^{[6]}$ and digital imaging with RGB color space analysis ${ }^{[7,8]}$. While several studies reported the use of colorimetry ${ }^{[4,9]}$ and spectrophotometry ${ }^{[10]}$ to assess SPT, Pershing et al. used spectrophotometry to objectively determine all six SPTs using only constitutive skin color independent of UVL-induced erythema ${ }^{[2]}$. The "gold standard" method of assessing skin pigmentation is spectrophotometry; however, it is difficult to perform spectrophotometry under clinical conditions.

Although skin pigmentation is not the only factor that plays a role in protection against sunburn ${ }^{[11]}$, it remains an important risk factor for skin cancer development. It has been reported that the low incidence of cutaneous malignancies in darker skinned groups is primarily a result of photoprotection contributed by increased epidermal melanin, which provides an inherent sun protection factor (SPF) of up to 13.4 in African American individuals $^{[12]}$. Thus, a clinically feasible and objective assessment of skin pigmentation remains an unmet need ${ }^{[4]}$.

The aim of this study was to assess SPT utilizing MI as determined by RGB images obtained both by digital camera and high resolution, high magnification videodermoscope.

\section{Materials and methods}

This single-center observational study assessed MI obtained from RGB digital images in adult male and female subjects with Fitzpatrick Skin Phototypes I-VI ${ }^{[13]}$. A sample of subjects, representing all SPTs and attended Northwestern University's Department of Dermatology, participated in the study. The sample consisted of subjects attending our large urban academic center (Chicago) during study enrollment. However, data on previous lifestyle and/or prior living in other geographic regions of the US and/or the world are unknown, and are therefore a limitation to this study and to the utility of SPT designations in general. The study was approved by the Northwestern University Institutional Review Board, and all participants provided written informed consent prior to participation.

Exclusion criteria were history of vitiligo, use of self-tanning products or tanning accelerators in the 6 weeks prior to enrollment, and recent history of prolonged sun exposure or indoor tanning. Inclusion criteria were being between age 18 to 70 , and able to read in English. A dermatologist administered the following questions: a) If after several months of not being in the sun, you stayed outdoors for about one hour at noon for the first time in the summer without sunscreen, what would happen to your skin?-Always sunburn, usually burn, burn minimally, burn rarely, or never sunburn; b) Over the next 7 days, would you develop a tan? -Never tan, tan lightly, tan moderately, or tan deeply. SPTs are assigned based upon the subjects' responses (Table 1). Subjects also self-reported age, gender, and ethnic background by completing an anonymous written survey.

Table 1. Fitzpatrick Skin Phototype Scale ${ }^{[1]}$

\begin{tabular}{ll}
\hline $\begin{array}{l}\text { Fitzpatrick Skin } \\
\text { Phototype }\end{array}$ & $\begin{array}{l}\text { Skin Reactions to Sunlight during the First } \\
\text { Summer Exposure }\end{array}$ \\
\hline I $(N=10)$ & $\begin{array}{l}\text { Always burns, never tan (painful burn at 24 h } \\
\text { and no tan at 7 days) }\end{array}$ \\
II $(N=13)$ & $\begin{array}{l}\text { Burn easy, then develop light tan (painful } \\
\text { burn at } 24 \text { h and a light tan at } 7 \text { days) }\end{array}$ \\
III $(N=8)$ & $\begin{array}{l}\text { Burn moderately, then develop light tan } \\
\text { (slightly tender burn at } 24 \text { h and moderate tan }\end{array}$ \\
at 7 days) & $\begin{array}{l}\text { Burn minimally/rarely, then develop moderate } \\
\text { tan (no burn at } 24 \text { h and a good tan at 7 days) }\end{array}$ \\
V $(N=10)$ & $\begin{array}{l}\text { No burns, always develops dark tan } \\
\text { No burns, no noticeable change in appearance }\end{array}$ \\
VI $(N=7)$ &
\end{tabular}

\section{Assessment of Melanin Index}

Two digital systems were used to capture images for 
analysis: a high resolution digital camera (Nikon D80 ${ }^{\circledR}$, Nikon Inc., USA) and a videodermoscopy system (Kit EasyScan Pico ${ }^{\circledR}$, Business Enterprise, Trapani, Italy). In order to minimize measurement bias and to ensure standardization of all parameters (distance, focus, source light and white balance), digital camera images were taken with a fixed light source at the same distance for all subjects. The camera was placed in manual mode, and white balance was established for each subject using Standard Kodak Color Palette ${ }^{\circledR}$. The videodermoscope utilized a fixed light intensity, fixed white balance, as well as fixed brightness and contrast to avoid re-calibration before each subject. Prior to videodermoscopy, antiseptic gel was applied to ensure smooth contact with the skin and to minimize stratum corneum light scattering. Images of the upper ventral arm (constitutive skin), $5 \mathrm{~cm}$ above the head of the humerus, were taken. These measurements were assessed for validity against the SPT determined by the dermatologist without adjustment for hair, eye color and presence of freckles.

Images taken with both instruments were stored electronically and processed by ImageJ software ${ }^{[14]}$. To obtain mean MI values, the formula (1) was used to measure melanin based on reflectance values of the red channel in the RGB image. This formula is equivalent to that used for narrow band spectrophotometers ${ }^{[8,15]}$.

(1) $A_{r, g, b}=100 \times \log _{10}\left(1 / R_{r, g, b}\right)$; where A, according to the model of Dawson et al. ${ }^{[16]}$, is the absorbance of the skin and $\mathrm{R}$ is the reflectance.

If it is assumed that MI can be obtained from the absorbance of the red channel $\left(A_{r}\right)$, then:

(2) $M I=A_{r}=100 \times \log _{10}\left(1 / R_{r}\right)$.

Reflectance of the skin is obtained from the ratio between the mean brightness value of the region of interest (ROI) and the white standard in the same ROI, hence:

(3) $\mathrm{R}_{\mathrm{r}}=\mathrm{S}_{\mathrm{r}} / \mathrm{W}_{\mathrm{r}}$

The final formula becomes:

(4) $\mathrm{MI}=100 \times \log _{10}\left(1 / \mathrm{S}_{\mathrm{r}} / \mathrm{W}_{\mathrm{r}}\right)=100 \times\left(\log _{10} 1-\log _{10} \mathrm{~S}_{\mathrm{r}} /\right.$ $\left.\mathrm{W}_{\mathrm{r}}\right)=100 \times\left(-\log _{10} \mathrm{~S}_{\mathrm{r}} / \mathrm{W}_{\mathrm{r}}\right)$.

In order to satisfy the final formula above and to make automated measurements, two of the authors (Di Loro $\mathrm{S}$ and Nardone B) created an ImageJ Java plugin where S is the mean brightness of skin in ROI and W is the known (previously measured) mean white brightness in the color palette in the same ROI.

\section{Statistical analysis}

Median MI obtained using both digital camera and videodermoscope were compared across SPT categories using the Kruskal-Wallis test. MI was also correlated with SPT using a Spearman correlation coefficient. A $p$ value $<0.05$ was considered statistically significant.

\section{Results}

58 subjects ( 20 male, 38 female) were enrolled in the study (mean age: 47 years; range: $20-89$ years), with skin types I-VI (I = 10; II = 13; III = 8; IV = 10; V = 10; VI $=7$ ), and various races (36 White, 19 Black, 3 Asian).

MI obtained by both digital camera and videodermoscope increased significantly as the SPT increased (Kruskas-Wallis test, $p=0.0044$ and $p<0.0001$, respectively). The MI obtained by the videodermoscope demonstrated a progressive gradient from Fitzpatrick skin type I through VI (Table 2). Of note, MI obtained by the digital camera showed an overlap among FSTs III and IV. MI did not correlate with the gender or age of the subject. Also, a statistically positive correlation with the assessed Fitzpatrick SPT was found for both digital camera and videodermoscope (Spearman correlation, $r=0.48$ and $p=$ $0.0001, r=0.84$ and $p<0.0001$, respectively).

Patient self-reported burn susceptibility significantly decreased as MI obtained by videodermoscope increased (Kruskal-Wallis test, $p<0.0001$ ). No statistical difference was found between MI obtained by videodermoscope and self-reported ability to tan (Kruskal-Wallis test, $p=0.21$ ).

Table 2. Melanin Index obtained from the digital camera and videodermoscope

\begin{tabular}{ccc}
\hline $\begin{array}{c}\text { Fitzpatrick Skin } \\
\text { Phototype* }\end{array}$ & Digital Camera & $\begin{array}{c}\text { Videodermo- } \\
\text { scope }^{2}\end{array}$ \\
\hline & $\begin{array}{c}\text { MI Median } \\
\left(1^{\text {st }}, 3^{\text {rd }} \text { quartile }\right)\end{array}$ & $\begin{array}{c}\text { MI Median } \\
\left(1^{\text {st }}, 3^{\text {rd }} \text { quartile }\right)\end{array}$ \\
I $(N=10)$ & $8.80(6.20,11.00)$ & $1.85(0.80,2.30)$ \\
II $(N=13)$ & $9.20(6.40,11.00)$ & $2.50(1.80,3.60)$ \\
III $(N=8)$ & $10.55(6.90,12.85)$ & $3.15(1.70,4.25)$ \\
IV $(N=10)$ & $10.95(7.70,13.00)$ & $6.30(3.00,12.80)$ \\
V $(N=10)$ & $12.20(7.20,14.50)$ & $33.35(15.00$, \\
VI $(N=7)$ & $14.70(14.20,20.10)$ & $41.20(27.30$, \\
Kruskal-Wallis test & $p=0.0044$ & $45.50)$ \\
\hline
\end{tabular}

* Determined by dermatologist's (JKR) assessment

${ }^{1}$ Positive Correlation with SPT for Digital Camera $(r=0.48, p=$ 0.0001 )

${ }^{2}$ Positive Correlation with SPT for Videodermoscope $(r=0.84, p<$ 0.0001 )

Abbreviations: $\mathrm{MI}=$ Melanin Index

\section{Discussion}

This study demonstrated that MI as determined from RGB images, in concert with high resolution digital photography or high resolution videodermoscopy, is an objective 
measure of skin pigmentation among all skin types. Moreover, the positive correlation with Fitzpatrick SPT suggests that this method for objective determination of MI provides a quantifiable assessment that may be useful to predict skin cancer risk in people of all skin types.

Over the last three decades, the Fitzpatrick SPT evolved from its original purpose of determining the amount of ultraviolet light (UVL) for treatment of New England psoriasis patients to become an assessment tool for skin cancer risk ${ }^{[17-19]}$. As part of this evolution, the original 4 skin types (I-IV), which assessed sun reactivity with standardized questions about the ease of sun burning and tanning reactions to the first exposure in the summer, were modified by adding SPT V and VI to include those with brown and black skin ${ }^{[1]}$. Our research demonstrated that the modifications to include people with skin of color were neither culturally sensitive nor accurate, as people of color were unable to respond to the questions of sunburn and tanning ${ }^{[20-22]}$. People with deep pigmentation of the skin did not report turning red or pink but rather experienced "irritation" after sun exposure ${ }^{[20-22]}$. Another limitation of the six Roman numeral Fitzpatrick SPT integers was the reliance upon a history of sunburn after the first exposure of summer. For those who reside in regions that have sun exposure all year (e.g. Arizona, Florida, California), the sunburning and tanning questions after the first exposure of summer was irrelevant. Lastly, in the 1990s, people began to apply sunscreens to prevent sunburns; thus, those with sun-sensitive skin may never have experienced sunburn and thus were unable to answer the question about ease of burning.

The heterogeneity of those with multi-ethnic backgrounds makes it difficult to assess susceptibility to skin cancer on the basis of skin color, which is predominantly determined by pigments such as hemoglobin, melanin, bilirubin and carotene ${ }^{[23,24,4]}$. There has been a tendency to group people of similar ethnic group into a single category of SPT, which introduces potential bias into the subjective assessment of SPT by investigators ${ }^{[25-27]}$. The limitations of Fitzpatrick SPT, especially in people with darker $\operatorname{skin}^{[28,29]}$, include recall bias, subjective bias by clinicians and subjects, lack of cultural sensitivity of the questions, and adherence to sun protection recommendations, resulting in children not having experienced prior sunburns. Although skin pigmentation is not the only factor that plays a role in protection against sunburn ${ }^{[11]}$, it remains an important risk factor for skin cancer development. It has been reported that the low incidence of cutaneous malignancies in darker skinned groups is primarily a result of photoprotection provided by increased epidermal melanin, which provides an inherent sun pro- tection factor (SPF) of up to 13.4 in African American individuals $^{[12]}$. Nonetheless, the Fitzpatrick SPTs are traditionally associated with skin cancer risk as follows: I, II - high risk; III, IV-moderate risk; and V, VI-very low risk of skin cancer development.

To date, reflectance methods such as spectrophotometry are considered the "gold standard" to determine melanin and hemoglobin content in the skin. Even if such instrumentation resulted in relatively non-confounded measures of melanin content, these instruments are expensive and require highly trained users, frequent calibration, as well as standard ambient room temperatures ${ }^{[30,2]}$. Such features make it clinically difficult to conduct melanin measurements, especially in pediatrics where prediction of those at risk may enhance sun protection ${ }^{[31]}$. Our findings are in part consistent with a recent study where a strong correlation between MI and individual typology angle (ITA) values were found, suggesting that either of these methods can be used to assess skin pigmentation depending on the relevance of the measurement outcome of the intended study. Determining skin type is necessary for understanding personal risk of sunburn and, by extension, personal risk of skin cancer ${ }^{[32]}$.

Videodermoscopy is widely applicable, non-invasive, portable and relatively inexpensive. Since dermoscopy is familiar to clinicians, novel technology utilizing videodermascope that allows assessment of SPT is likely to be readily adaptable to practice. While it is difficult to achieve standardization for distance, brightness and identical pose with a digital camera, imaging with videodermoscopy involves a non-invasive, easy-to-use, portable device that provides a high resolution digital image with rapid and easy calibration essential to ensuring color reproducibility. Videodermoscope also provides objective and reproducible measurements to determine MI and to efficiently predict skin response to sunlight. Importantly, under clinical conditions, MI measurements are actually more consistent with a videodermoscope than with a digital camera.

\section{Conclusion}

Although these findings warrant further investigation in a larger and more racially diverse subject population in order to validate this methodology, the data suggest that quantification of pigmentation in a digital image holds promise as a simple, non-invasive, practical and objective approach to more reliably document skin phototypes, particularly for those who are at high risk of developing skin cancer. Software and hardware, with standardization, may undergo development and be adaptable for quanti- 
fication of change in pigment associated with biological processes such as stimulation of melanogenesis by hormones and UVL.

\section{Conflict of interest}

The authors declared no potential conflict of interest with respect to the research, authorship, and/or publication of this article.

\section{References}

1. Fitzpatrick TB. The validity and practicality of sun-reactive skin types I through VI. Arch Dermatol 1988; 124(6): 869-871. doi:10.1001/archderm.1988.01670060015008.

2. Pershing LK, Tirumala VP, Nelson JL, Corlett JL, Lin AG, et al. Reflectance spectrophotometer: The dermatologists' sphygmomanometer for skin phototyping? J Invest Dermatol 2008; 128(7): 1633-1640. doi: 10.1038/sj.jid.5701 238.

3. Stamatas GN, Zmudzka BZ, Kollias N, Beer JZ. In vivo measurement of skin erythema and pigmentation: New means of implementation of diffuse reflectance spectroscopy with a commercial instrument. Br J Dermatol 2008; 159(3): 683-690. doi: 10.1111/j.1365-2133.2008.08642. $\mathrm{x}$.

4. Rubegni P, Cevenini G, Flori ML, Fimiani M, Stanghellini E, et al. Relationship between skin color and sun exposure history: a statistical classification approach. Photochem Photobiol 1997; 65(2): 347-351. doi: 10.1111/ j.1751-1097.1997.tb08569.x.

5. Treesirichod A, Chansakulporn S, Wattanapan P. Correlation between skin color evaluation by skin color scale chart and narrowband reflectance spectrophotometer. Indian J Dermatol 2014; 59(4): 339-342. doi: 10.4103/ 0019-5154.135476.

6. Ries F, Kapoustina V, Kron A, Fink A, Radle M. Estimation of skin phototypes with optical parameters: An experimental study using newly developed fibre optic detection device. Int J Cosmet Sci 2013; 35(1): 50-56. doi: 10.1111/ics.12003.

7. Yamamoto T, Takiwaki H, Arase S, Ohshima H. Derivation and clinical application of special imaging by means of digital cameras and Image $\mathbf{J}$ freeware for quantification of erythema and pigmentation. Skin Res Technol 2008; 14(1): 26-34. doi:10.1111/j.1600-0846.2007.00256.x.

8. Takiwaki H, Shirai S, Kanno Y, Watanabe Y, Arase S. Quantification of erythema and pigmentation using a videomicroscope and a computer. Br J Dermatol 1994; 131(1): 85-92. doi: 10.1111/j.1365-2133.1994.tb08462. $\mathrm{x}$.
9. Poon TS, Kuchel JM, Badruddin A, Halliday GM, Barnetson RS, et al. Objective measurement of minimal erythema and melanogenic doses using natural and solarsimulated light. Photochem Photobiol 2003; 78(4): 331336. doi: 10.1562/0031-8655(2003)078<0331: OMO$\mathrm{MEA}>2.0 . \mathrm{CO} ; 2$

10. Kollias N, Baqer A, Sadiq I. Minimum erythema dose determination in individuals of skin type V and VI with diffuse reflectance spectroscopy. Photodermatol Photoimmunol Photomed 1994; 10(6): 249-254.

11. Abeyama K, Eng W, Jester JV, Vink AA, Edelbaum D, et al. A role for NF-kappaB-dependent gene transactivation in sunburn. J Clin Invest 2000; 105(12): 1751-1759. doi: 10.1172/JCI9745.

12. Narayanan DL, Saladi RN, Fox JL. Ultraviolet radiation and skin cancer. Int J Dermatol 2010; 49(9): 978-986. doi: 10.1111/j.1365-4632.2010.04474.x.

13. Nardone B, Haley AC, Martini M, Brown K, West DP, et al. Skin melanin index obtained from digital photography and videodermoscopy correlates with dermatologist assessment of skin type. J Invest Dermatol 2010; 130: S140.

14. Rasband W. ImageJ. U.S. National Institutes of Health. Bethesda, Maryland, USA. 1997-2009. Accessed Feb. 22, 2016. Available from: http://rsb.info.nih.gov/ij/.

15. Stamatas GN, Zmudzka BZ, Kollias N, Beer JZ. Noninvasive measurements of skin pigmentation in situ. Pigment Cell Res 2004; 17(6): 618-626. doi: 10.1111/j. 1600-0749.2004.00204.x.

16. Dawson JB, Barker DJ, Ellis DJ, Grassam E, Cotterill JA, et al. A theoretical and experimental study of light absorption and scattering by in vivo skin. Phys Med Biol 1980; 25(4): 695-709. doi: 10.1088/0031-9155/25/4/008.

17. Stern RS, Momtaz K. Skin typing for assessment of skin cancer risk and acute response to UV-B and oral methoxsalen photochemotherapy. Arch Dermatol 1984; 120(7): 869-873. doi: 10.1001/archderm.1984.01650430055010.

18. Diette KM, Momtaz K, Stern RS, Arndt KA, Parrish JA. Role of ultraviolet A in phototherapy for psoriasis. J Am Acad Dermatol 1984; 11(3): 441-447. doi: 10.1016/ S0190-9622(84)70188-5.

19. Fitzpatrick TB. Soleil et peau (French) [Sun and Skin]. J Med Esthet 1975; 2: 33-34.

20. Robinson JK, Joshi KM, Ortiz S, Kundu RV. Melanoma knowledge, perception, and awareness in ethnic minorities in Chicago: Recommendations regarding education. Psycho-Oncology 2010; 20(3); 313-320. doi: 10.1002/ pon.1736.

21. Eilers S, Bach DQ, Gaber R, Blatt H, Guevara Y, et al. Accuracy of self-report in assessing Fitzpatrick skin phototypes I through VI. JAMA Dermatol 2013; 149(11): 
1289-1294. doi: 10.1001/jamadermatol.2013.6101.

22. Wright CY, Wilkes M, du Plessis JL, Reeder AI. Selfreported skin colour and erythemal sensitivity vs. objectively measured constitutive skin colour in an African population with predominantly dark skin. Photodermatol Photoimmunol Photomed 2015; 31(6): 315-324. doi: 10.1111/phpp.12191.

23. Chan JL, Ehrlich A, Lawrence RC, Moshell AN, Turner ML, et al. Assessing the role of race in quantitative measures of skin pigmentation and clinical assessments of photosensitivity. J Am Acad Dermatol 2005; 52(4): 609-615. doi:10.1016/j.jaad.2004.03.051.

24. Lee JH, Kim TY. Relationship between constitutive skin color and ultraviolet light sensitivity in Koreans. Photodermatol Photoimmunol Photomed 1999; 15(6): 231-235. doi: 10.1111/j.1600-0781.1999.tb00095.x.

25. Chung JH, Koh WS, Youn JI. Relevance of skin phototyping to a Korean population. Clin Exp Dermatol 1994; 19(6): 476-478. doi: 10.1111/j.1365-2230.1994. tb01250. $\mathrm{x}$.

26. Park SB, Suh DH, Youn JI. Reliability of self-assessment in determining skin phototype for Korean brown skin. Photodermatol Photoimmunol Photomed 1998; 14(5-6): 160-163. doi: 10.1111/j.1600-0781.1998.tb00035.x.

27. Stanford DG, Georgouras KE, Sullivan EA, Greenoak GE.
Skin phototyping in Asian Australians. Australas J Dermatol 1996; 37(Suppl 1): S36-S38. doi: 10.1111/ j.14400960.1996.tb01078.x.

28. Kawada A. Risk and preventive factors for skin phototype. J Dermatol Sci 2000; 23(Suppl 1): S27-S29. doi: 10.1016/S0923-1811(99)00074-2.

29. Sanclemente G, Zapata JF, Garcia JJ, Gaviria A, Gomez LF, et al. Lack of correlation between minimal erythema dose and skin phototype in a Colombian scholar population. Skin Res Technol 2008; 14(4): 403-409. doi: 10.1111/j.1600-0846.2008.00306.x.

30. Daniel LC, Heckman CJ, Kloss JD, Manne SL. Comparing alternative methods of measuring skin color and damage. Cancer Causes Control 2009; 20(3): 313-321. doi: 10.1007/s10552-008-9245-3.

31. Naldi L, Altieri A, Imberti GL, Gallus S, Bosetti C, et al. Sun exposure, phenotypic characteristics, and cutaneous malignant melanoma. An analysis according to different clinico-pathological variants and anatomic locations (Italy). Cancer Causes Control 2005; 16(8): 893-899. doi: 10.1007/s10552-005-2300-4.

32. Wilkes M, Wright CY, du Plessis JL, Reeder A. Applicable skin photosensitivity assessments. JAMA Dermatol 2015; 151(8): 902-903. doi: 10.1001/jamadermatol.2015. 0351. 